\title{
Preparation of Spent Bleaching Earth-Supported Calcium from Limestone as Catalyst in Transesterification of Waste Frying Oil
}

\author{
Noor Hindryawati ${ }^{1, \bowtie}$, Daniel $^{1}$, Erwin $^{1}$, Gaanty Pragas Maniam ${ }^{2,3}$

\section{DOI 10.15294/jbat.v6i1.9860}

${ }^{1}$ Faculty of Mathematic and Natural Sciences, Mulawarman University, Gunung Kelua, 75113

Samarinda, East Kalimantan, Indonesia

${ }^{2}$ Faculty of Industrial Sciences and Technology, Universiti Malaysia Pahang, Lebuhraya Tun Razak, 26300 Gambang, Kuantan, Pahang, Malaysia

${ }^{3}$ Central Laboratory, Universiti Malaysia Pahang, Lebuhraya Tun Razak, 26300 Gambang, Kuantan, Pahang, Malaysia

\begin{tabular}{l} 
Article Info \\
\hline Article history: \\
Accepted \\
March 2017 \\
Approved \\
May 2017 \\
Published \\
June 2017 \\
\hline Keywords : \\
Transesterification; \\
Heterogeneous base \\
catalyst; Waste \\
frying oil; Spent \\
bleaching earth; \\
Methyl ester \\
\hline
\end{tabular}

\begin{abstract}
An investigation was conducted on palm oil refinery waste-spent bleaching earth (POR-SBE), POR-SBE supported by calcium as catalysts for methyl esters production through transesterification process using waste frying oil. The catalysts showed longer lasting activity than the traditional alkali catalysts. The optimum conditions for the process were: Ca-PORSBE catalyst amount $7 \%$; methanol to oil molar ratio $12: 1$; and a reaction duration is $4 \mathrm{~h}$. The process was able to transesterify oil to methyl esters at $96.8 \%$ conversion at $65^{\circ} \mathrm{C}$. The catalysts were easily separated from the reaction mixture and the final product met selected biodiesel fuel properties in accordance with European Standard EN 14214.
\end{abstract}

\section{INTRODUCTION}

Biodiesel is one of the alternative fuel that very attracting attention worldwide as blended fuel. However, operational cost (about 80\%) exerts the major impact on the overall production cost of biodiesel (Demirbas, 2010). Production biodiesel with simple method and cheaper cost production recently become interest topic area for researcher due to develop a new method. Biodiesel is mainly prepared from edible oil, the other issues are utilizing edible oil for biodiesel that competes with food needs and has a definite impact on global food security and agricultural land. One of the ways to counter this issue is to use waste oil as feedstock for biodiesel production.

In Indonesia, palm oil is the common oil used for production of biodiesel as it is beneficially due to locally available and accessible. This is because Indonesia is one of the major producers and exporters of palm oil. Furthermore, waste frying oil (WFO) and waste oil from palm oil industry can be used for production of biodiesel. Conversion of waste oil into valuable product has add value to the sustainability of biodiesel as the production cause less or no harm to the environment and thus able to replace petroleum fuel and continue for a long time.

(C) 2017 Semarang State University

\footnotetext{
$\bowtie$ Corresponding author:

Faculty of Mathematic and Natural Sciences, Mulawarman University,

Gunung Kelua, 75113, Samarinda, East Kalimantan, Indonesia

E-mail: ienwati@yahoo.com
} 
Spent bleaching earth (SBE) is one of the major wastes from the edible oil industry. In Indonesia alone, with an annual production of about 18 million tonnes of crude palm oil (CPO), more than 100,000 tonnes of SBE is generated yearly. The most common way of disposing of the oil laden SBE is by dumping into landfill. Using $\mathrm{SBE}$ as a feedstock in biodiesel production has been reported, but again, the spent bleaching earth (SBE) is a waste without any appreciable use. Bleaching earth is mainly composed of smectite, an aluminosilicate mineral with variable net negative charge, which is balanced by $\mathrm{Na}, \mathrm{Ca}, \mathrm{Mg}$ and, or, $\mathrm{H}$ adsorbed externally on interlamellar surfaces. The native metal is very low in content and in unstructured pattern. When SBE is acid-activated, hydrogen ions attack the aluminosilicate layers via the interlayer region. This attack alters the structure, chemical composition and physical properties of the earth. The hydrogen ion on interlayer could exchange by substitution of metal. As such, the metals presence can be designed in more structural manner and in desired amount.

In this work, a novel approach is proposed where the SBE supported calcium from limestone will be used as a catalyst in the very same reaction of transesterification of waste frying oil. Heterogeneous catalysts have the potential to address the disadvantage issues created by the conventional caustic homogeneous catalysts as they provide easier separation techniques, leave the product free of catalyst impurities and exclude the requirement for product neutralization and purification steps.

\section{MATERIAL AND METHODS}

\section{Material}

Fresh SBE was collected from Local oil palm industry (Paser), limestone was collected from Puger Mountain, Java. Analytical grade methanol, $n$-hexane, petroleum ether (PE), chloroform $\left(\mathrm{CHCl}_{3}\right)$, sulphuric acid (95-97\%), ethanol, Thin Layer Chromatography (TLC) $(20 \times 20 \mathrm{~cm}$, silica gel 60 F254) of HPTLC grade were purchased from MERCK (Germany). phenolphthalein $\left(\mathrm{H}_{-}=8.2\right)$, 2,4-dinitroaniline $\left(H_{-}=15.0\right)$ and 4-nitroaniline $\left(\mathrm{H}_{-}=18.4\right)$ are purchased from Bendosen. Methyl heptadecanoate as an internal standard GC grades (> $99.1 \%$ ) were obtained from Sigma-Aldrich (Switzerland), whereas iso-propanol, glacial acetic acid, potassium iodide, starch, sodium thiosulphate
$\left(\mathrm{Na}_{2} \mathrm{~S}_{2} \mathrm{O}_{3}\right)$, and benzene were from Merck KGaA (Darmstadt, Germany).

\section{Extraction of oil via Ultrasound Extraction from SBE}

The fresh SBE is dried overnight in oven at $110^{\circ} \mathrm{C}$ and then grinded into fine particle size. The oil adsorbed on SBC is extracted via ultrasound with $n$-hexane (non-polar solvent) according to the method applied in study of Maniam et al. (2013). For optimization of oil extraction, $10 \mathrm{~g}$ of SBC is extracted with $10 \mathrm{~g}$ hexane via ultrasound at temperature of $65^{\circ} \mathrm{C}$ for $15 \mathrm{~min}, 30 \mathrm{~min}, 45 \mathrm{~min}$, and $60 \mathrm{~min}$ respectively. The sonicated mixture is then centrifuge at $7000 \mathrm{rpm}$ for $15 \mathrm{~min}$ to obtain clear supernatant layer. The supernatant solution is transferred to pre-weight rotary flask and solvent is recovered via rotary evaporation. The oil content is calculated by dividing mass of oil extracted ( $\left.\mathrm{M}_{\text {oil }}\right)$ with mass of SBE (M $\left.\mathrm{MBE}_{\mathrm{SB}}\right)$ in $\mathrm{g}$ as expressed in Equation 1.

$$
\text { Oil wt. } \%=\mathrm{M}_{\mathrm{oil}} / \mathrm{M}_{\mathrm{SBE}} \times 100
$$

\section{Catalyst Preparation}

The limestone were cleaned using water to remove dirt matters, then dried in an oven at $105^{\circ} \mathrm{C}$ overnight and ground using pestle and mortar to obtain the gross powder continue with sieved through 200 mesh before being subjected to heat treatment in the furnace at $900^{\circ} \mathrm{C}$ for $2 \mathrm{~h}$. Ca-PORSBE were prepared using the wet impregnation method. Spent bleaching earth free oil $(50 \mathrm{~g})$ was added into $150 \mathrm{~mL}$ distilled water and was placed into $250 \mathrm{~mL}$ flask held by mechanical stirring for 5 hours. The Ca-impregnated SBE sample was prepared at $50 \%$ wt $\mathrm{CaO}$ limestone (from SBE weight). It then was dried in an oven at $120^{\circ} \mathrm{C}$ for $3 \mathrm{~h}$. Upon drying, the Ca-POR-SBE particle was calcined at $850^{\circ} \mathrm{C}$ for 2 hour.

\section{Catalyst Characterization}

The size and morphology of Ca-POR-SBE catalyst was observed by FE-SEM (JSM-7800F), the crystallinity characterized by X-ray diffraction (Rigaku) and surface area of catalyst was analyse by surface area analysis. The base strengths of the catalyst (H_) were determined by using Hammett indicators. The following Hammett indicators were used: phenolphthalein $\left(\mathrm{H}_{-}=8.2\right), 2$,4-dinitroaniline $\left(\mathrm{H}_{-}=15.0\right)$ and 4-nitroaniline $\left(\mathrm{H}_{-}=18.4\right)$. About 25 $\mathrm{mg}$ of catalyst was shaken with $5.0 \mathrm{~mL}$ of a solution 
Table 2. Characterization of WCOs.

\begin{tabular}{lllll}
\hline Test & WFO $_{1}$ & WFO $_{2}$ & WFO $_{3}$ & WFO $_{4}{ }^{*}$ \\
\hline Acid Value (mg/KOHg) & 4.77 & 6.69 & 2.51 & 3.54 \\
FFA ( \%) & 2.39 & 3.36 & 1.23 & 1.67 \\
Water content (wt.\%) & 0.12 & 0.12 & 0.12 & 0.11 \\
Density $\left(\mathrm{g} / \mathrm{cm}^{3}\right)$ & 0.91 & 0.91 & 0.91 & 0.91 \\
Viscosity (cP) & 68.20 & 69.20 & 67.6 & 64.00 \\
\hline
\end{tabular}

Note: $\mathrm{WFO}_{1}$ : Restaurant in samarinda; $\mathrm{WFO}_{2}$ : Restaurant in samarinda seberang; $\mathrm{WFO}_{3}$ :

Domestic house; $\mathrm{WFO}_{4}$ : Cafetaria in Mulawarman University (* as a feedstock)

of Hammett indicator diluted with methanol, and left to equilibrate for $2 \mathrm{~h}$. After the equilibration, the colour change of the solution was noted.

\section{Transesterification}

The conversion of waste frying oil to methyl ester (biodiesel) was performed in a $50 \mathrm{ml} 2$ neck round bottom flask equipped with a reflux condenser and magnetic stirrer. The transesterification reaction between oil and methanol was carried out in the liquid phase under atmospheric pressure, at $65{ }^{\circ} \mathrm{C}$ with continuous stirring. The effect of molar ratio of methanol to oil, catalyst/oil weight ratio and reaction time on the conversion of triglycerides to biodiesel were investigated. After the transesterification, the reaction mixture was allowed to cool. Biodiesel was isolated by centrifugation to further separate the layers (methyl ester, glycerol and catalyst, and then excessive amount of methanol and water was evaporated before the chromatographic analysis. The concentration of FAME in the sample was quantified using GC-FID (Clarus 500 GC-FID, PerkinElmer) by following the European regulation procedure EN 14214 with polar capillary column (DB-Wax, $30 \mathrm{~m}$ $x 0.25 \mathrm{~mm}$ i.d. $\mathrm{x} 0.25 \mu \mathrm{m}$ ) using methyl heptadecanoate as an internal standard. Peaks of methyl ester were identified by comparing them with their respective standards. The quality of the final product was tested for viscosity, acid number, free fatty acid (FFA) and density by following the EN 14214.

\section{RESULT AND DISCUSSIONS}

\section{Quality parameter of Feedstock}

The types of feedstock were used in this study is waste frying oil (WFO). WFO was characterized in term of acid value, density, water content and viscosity (Table 1). As oleic acid is the predominant fatty acid in WFO. The acid value of WFO is $3.54 \pm 0.05 \mathrm{mg} / \mathrm{KOH}$ g (equivalent to 1.77
$\%$ FFA as oleic acid). The relatively high viscosity is due to the two main factors influencing viscosity i.e. structure and intermolecular forces (Refaat, 2009). Viscosity increases with degree of saturation and the attractive intermolecular forces. Factors such as double-bond configuration; cis double-bond configuration resulted in lower viscosity than the trans. The chain length (number of carbon atoms) was also influence the viscosity (Knothe \& Steidley, 2005). It has been reported by Rodrigues et al. (2006) that the presence of one double bond lead to higher viscosity, than two or three double bonds.

Table 1. Quality parameters of WFO.

\begin{tabular}{ll}
\hline Parameter & WFO \\
\hline Acid value $(\mathrm{mgKOH} / \mathrm{g})$ & $3.54 \pm 0.05$ \\
Density $\left(\mathrm{kg} . \mathrm{m}^{-3}\right)$ & $911 \pm 1.9$ \\
Water content (wt.\%) & $0.28 \pm 0.06$ \\
Viscosity (cP) & $64.00 \pm 1.8$ \\
\hline
\end{tabular}

The characteristic of WFO from different sources is presented in Table 2. The acid value, FFA, water content, density and viscosity of WFOs from different sources in Samarinda were similar, although the acid value and viscosity have small differences depending on the WFO sources. Vegetable oils used in industrial or household frying undergo degradation by hydrolytic and oxidative reactions, both processes being responsible for changes in the chemical and physical properties, compared to the fresh oil (Rossi \& Ramos, 2000). Frying will change the chemical and physical properties of the oil, such as viscosity and free fatty acid content, colour change, iodine number drop, change in refraction and the oil's increased foaming property and the oil becomes darker and develops an unpleasant odour (Farhoosh \& TavassoliKafrani, 2011; and Kleinová et al., 2013).

The major fatty acid of WFO is oleic acid, the comparison with previous work was investigated and tabulated in Table 3 . The unsaturated fatty acid consist of $62.85 \%$, while the saturated components is accounted as $37.15 \%$. The palmitic acid in WCF was lower than RBD-PO, it 
Table 3. Fatty acid composition of WFO.

\begin{tabular}{lll}
\hline Fatty acid & \multicolumn{2}{c}{ Composition (\%) } \\
\cline { 2 - 3 } & Present work & $\begin{array}{l}\text { Previous work } \\
\text { (Atapour et al., 2014) }\end{array}$ \\
\hline Saturated & & \\
Lauric $\left(\mathrm{C}_{12: 0)}\right.$ & 0.84 & 0.20 \\
Myristic $\left(\mathrm{C}_{14: 0}\right)$ & 1.33 & 0.70 \\
Palmitic $\left(\mathrm{C}_{16: 0}\right)$ & 30.36 & 28.9 \\
Stearic $\left(\mathrm{C}_{18: 0}\right)$ & 4.62 & 4.00 \\
Arachidic $\left(\mathrm{C}_{20: 0}\right)$ & - & 0.30 \\
Sub total & $\mathbf{3 7 . 1 5}$ & $\mathbf{3 4 . 1 0}$ \\
Unsaturated & & \\
Palmitoleic $\left(\mathrm{C}_{16: 1}\right)$ & 3.39 & 0.20 \\
Oleic $\left(\mathrm{C}_{18: 1)}\right.$ & 40.90 & 37.30 \\
Linoleic $\left(\mathrm{C}_{18: 2}\right)$ & 17.57 & 26.80 \\
Linolenic $\left(\mathrm{C}_{18: 3}\right)$ & 0.99 & 1.10 \\
Sub total & $\mathbf{6 2 . 8 5}$ & $\mathbf{6 5 . 1 0}$ \\
Others & & 0.50 \\
Total & $\mathbf{1 0 0 . 0 0}$ & $\mathbf{1 0 0 . 0 0}$ \\
\hline
\end{tabular}

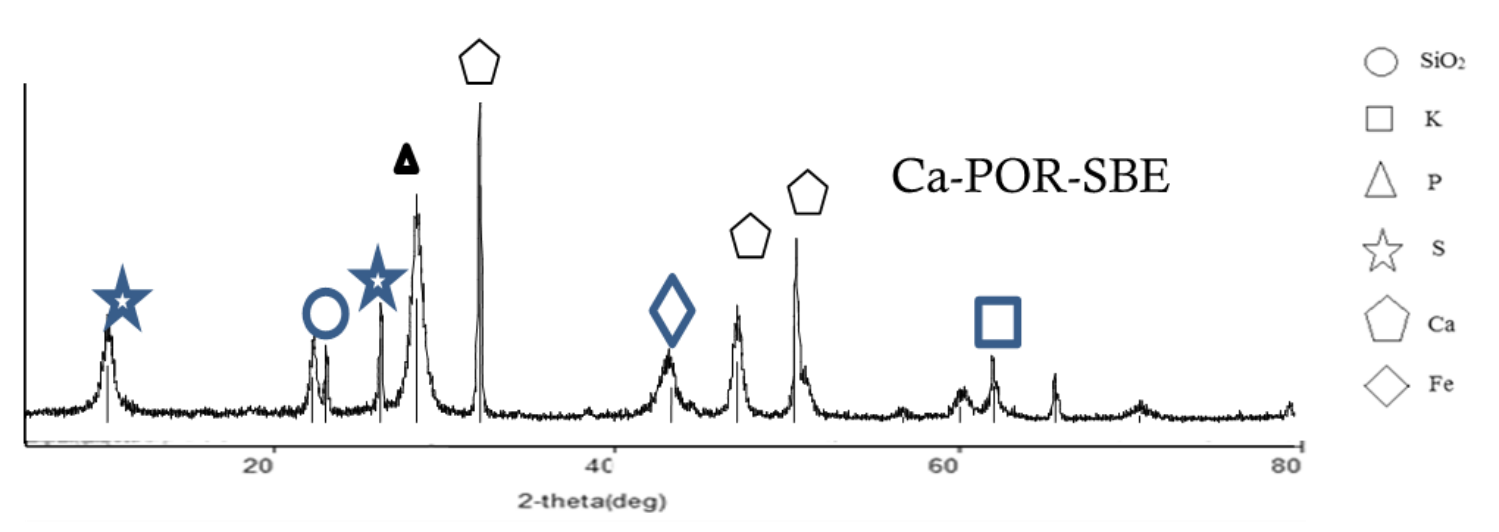

Figure 1. XRD Difractogram of the catalyst.

could be that the cooking oil was used to fry chicken or fish causing the fatty acid composition of the waste oil to resemble the composition of chicken and fish. Boey et al. (2011d) reported, chicken fat oil content $6.3 \%$ palmitoleic acid. In line with Hemung et al. (2010), catfish oil has $2.14 \%$ of palmitoleic acid. The WFO could be used to fry chicken which justify the presence of palmitoleic acid $\left(\mathrm{C}_{16: 1}\right)$. Originally in RBD-PO the palmitoleic acid is not usually present. WFO properties are much different compared with fresh cooking oil. During frying process, heat and water accelerates the hydrolysis of triglycerides and increases the free fatty acid content in oil. The problem with waste cooking oil is that they usually contain large amount of free fatty acids.

\section{Catalyst Characterization}

The XRD patterns for Ca-POR-SBE shows the intense diffraction peaks of the element and indicate that it is in crystalline form. Potassium, phosphorus, gamma-Fe, calcium and cyclo-18sulphur are the elements that have been found in calcined Calcium over SBE. Since SBE contains silica, it can act as support material in the formation of basic catalyst (Figure 1).

FESEM image of the POR-SBE and CaPOR-SBE catalyst is clearly shown in Figure 2. The micrograph of POR-SBE (Figure 2a) demonstrated amorphous material with heterogeneous spherical particle, in contrast with Ca-POR-SBE shown calcium species could be found distributed on the surface of the support, which contributes to basicity 


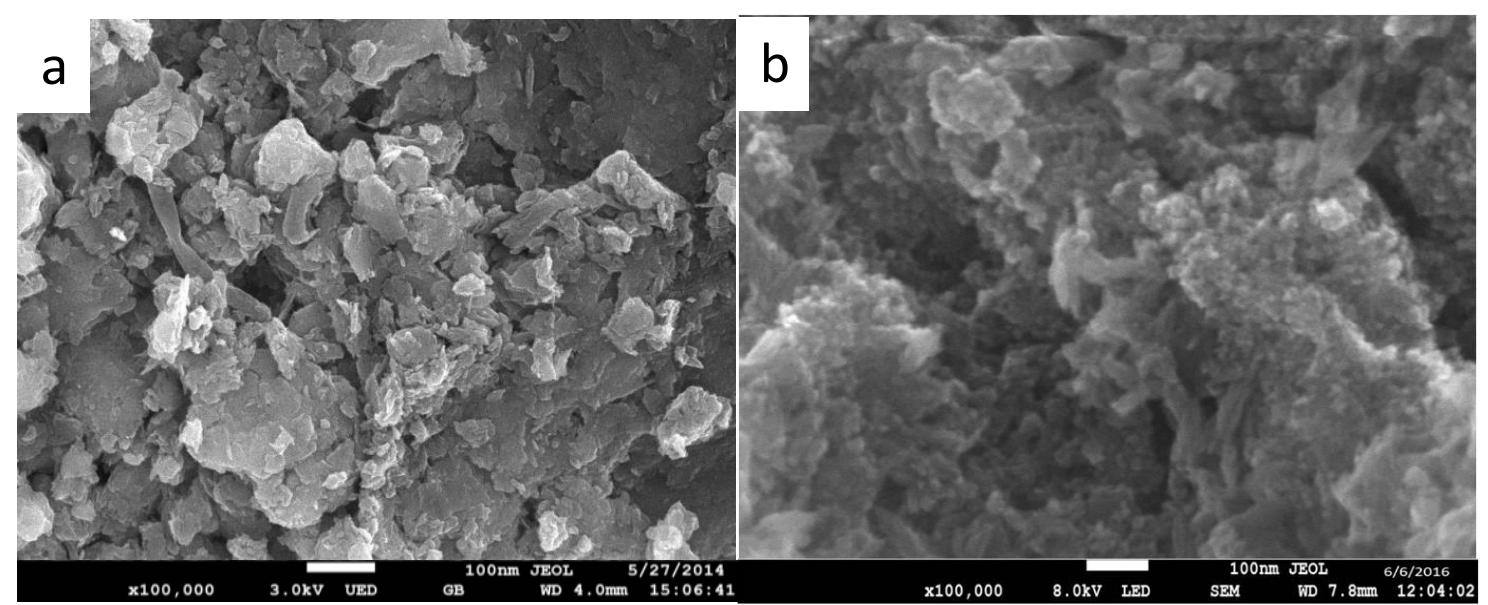

Figure 2. FESEM image of (a) POR-SBE, (b) Ca-POR-SBE catalyst.

Table 4. BET profile of POR-SBE and Calcium impregnated to POR-SBE.

\begin{tabular}{llll}
\hline Sample & $\begin{array}{l}\text { BET surface } \\
\text { area }\left(\mathrm{m}^{2} / \mathrm{g}\right)\end{array}$ & $\begin{array}{l}\text { Pore } \\
\text { volume }\left(\mathrm{cm}^{3} / \mathrm{g}\right)\end{array}$ & Pore size $(\AA)$ \\
\hline $\mathrm{DSBE}$ & 120.1647 & 0.243180 & 83.2033 \\
$\mathrm{Ca} /$ POR-SBE & 40.9721 & 0.222066 & 240.6231 \\
\hline
\end{tabular}

of the catalyst. The reflux method, continued by calcination at $850^{\circ} \mathrm{C}$, made the spherical crystals on the surface agglomerate with a porous appearance in Ca_POR-SBE. This structure also indicates that there is possible increase in contact between the catalyst and the substrates, which will lead in better efficiency of transesterification because the granules made up of smaller granules and porous netlike structure.

BET was conducted to study catalyst pore size by sorption of nitrogen gas at liquid nitrogen temperature $\left(-196^{\circ} \mathrm{C}\right)$.

Both samples showed slightly different reading due to pre-treatment that has been adopted on them (Table 4). DSBE which non-impregnated with $\mathrm{CaO}$ show high surface area. These characteristics are obviously different from the $\mathrm{Ca}^{2+}$ impregnated over SBE catalyst. The impregnation of $\mathrm{Ca}$ on SBE surface has reduced the surface area and pore volume. This is because during the impregnation, the $\mathrm{CaO}$ molecules filled the available pores in the DSBE, leading to a decrease of the surface area and pore volume of the catalyst while increase of the pore size of the catalyst. After impregnation the pore sizes of $\mathrm{Ca} / \mathrm{POR}-\mathrm{SBE}$ more large than SBE, $\mathrm{CaO}$ supported deoiled DSBE shown as a mesoporous solid, and the surface area of the catalyst slightly decreases due to $\mathrm{CaO}$ has filled the pores and cavity on the SBE surface.

\section{Transesterification Waste Frying Oil Effect of catalyst amount.}

The effect of catalyst amount was investigated by varying 1 to $10 \mathrm{wt} \%$, it was revealed in Figure 3. In the illustration shown, the increasing catalyst amount the conversion of the methyl ester increase step by step, the optimum condition was achieved at $5 \mathrm{wt} \%$ of amount catalyst for Ca-POR$\mathrm{SBE}$ and $7 \mathrm{wt} \%$ for Ca-POR-SBE. This is because the low amount of catalyst cannot support the oil conversion. The methyl ester conversion reaches an optimal value when the catalyst amount reaches at 5 wt. $\%$ and 7 wt. $\%$ with methyl ester conversion above $96.5 \%$, this is because the contact opportunity of the catalyst and the reactant directly affect to the conversion. Furthermore, increasing the catalyst amount beyond the optimal value has a negative effect on the purity of the final product. After achieved of optimum condition point, the methyl ester conversion will sustainable decreased. It is probably, when the amount of the catalyst increased, more products were adsorbed, caused presence of high soap content which will leads to the low activity. Furthermore caused esters conversion decreased.

\section{Effect of methanol/oil molar ratio}

The effect of methanol/oil molar ratio was observed, five different varied from 6:1, 9:1, 12:1, 

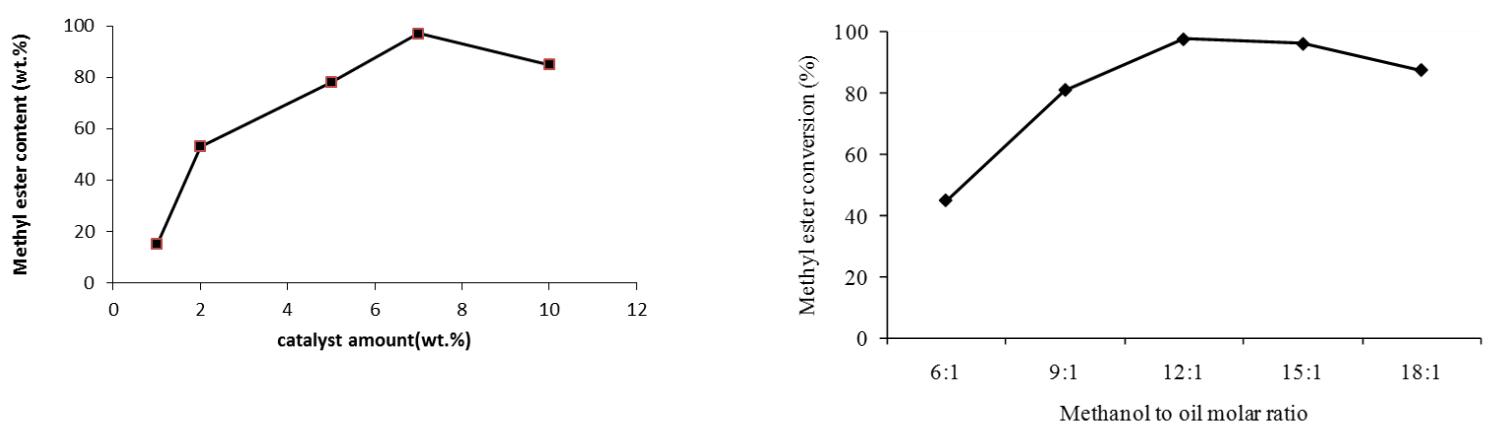

Figure 3. The effect of catalyst amount on methyl Figure 4. The effect methanol to oil molar ratio on esters conversion. methyl esters conversion.

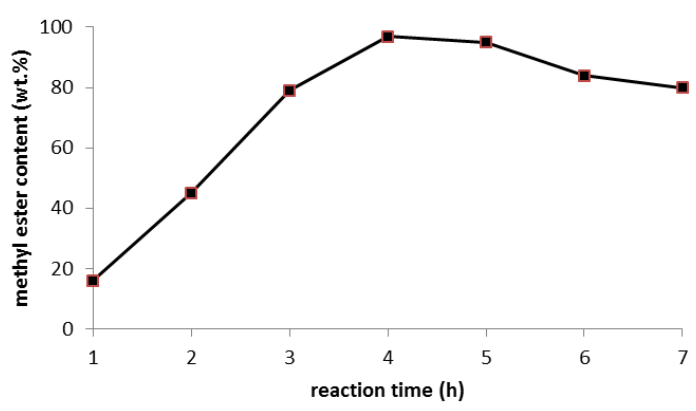

Figure 5. The effect of reaction time on methyl esters conversion.

15:1 and 18:1 Methanol/oil is one of the important variables that affect in the transesterification reaction. The maximum methyl ester conversion was achieved at 12:1 methanol/oil molar ratio with obtained high conversion above $96.7 \%$ methyl ester conversion. However, a drop of methyl ester conversion was seen after the methanol/oil molar ratio at 15:1 and then was sustainable decreased until 18:1 methanol/oil molar ratio. Increasing further the molar ratio did not cause any appreciable change in the reaction activity. This may due to the high ratio is too large and can cause the difficult separation of methyl esters and glycerol as well as complicates the methanol removal process.

\section{Effect of reaction duration}

The effect of the reaction duration is shown in Figure 5. The reaction duration was varied from 1 to $7 \mathrm{~h}$. From Figure 5, it can be seen that for the catalyst amount of $7 \mathrm{wt} . \%$, the ME content increased within the first $2 \mathrm{~h}$ and reached as high as 49 wt.\%. Further, with an increase in the reaction duration more than $4 \mathrm{~h}$, the methyl esters content increased and remained almost constant as a result of near equilibrium at $96.8 \%$ However, the conversion increased step by step until reaction time at $4 \mathrm{~h}$. Moreover, it is interesting to note that for longer reaction duration the conversion decreases, which may due to the reverse reaction, resulting in a loss of esters as well as causing more fatty acid to form soap. It is the same trend for Ca-POR-SBE, but the optimum reaction time is $4 \mathrm{~h}$ with the methyl ester conversion reach $96.8 \%$.

Figure 6 presents chromatogram of methyl esters from WFO and the internal standard (methyl heptadecanoate). The oleic acid is the major fatty acid followed by palmitic acid and linoleic acid. Methyl esters of stearic, palmitoleic, myristic, linolenic, and lauric are present as minor constituents.

\section{The physical and chemical properties of methyl ester}

The physical and chemical properties of the prepared biodiesel are demonstrated in Table 4. Although many other parameters need to be analysed in order to confirm the final product as a fuel, these nine parameters can serve as indicators of the product for the purpose to be used as a fuel.

The properties of ME (biodiesel) are compared with those of EN14214 biodiesel standards. The present results obtained show that the transesterification process improved the fuel properties of the oil. The methyl esters of WFO is above $96.5 \%$, this value is follow with EN14214 biodiesel standard. 


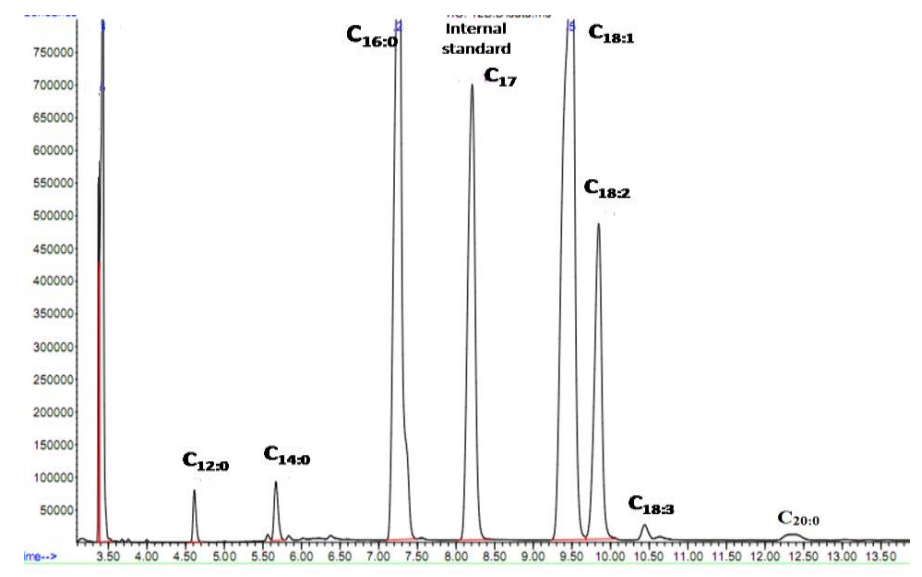

Figure 6. GC-FID Chromatogram.

Table 4. Physicochemical properties of methyl esters

\begin{tabular}{|c|c|c|c|}
\hline Parameters & Unit & $\begin{array}{c}\text { Catalysts } \\
\text { Ca-POR-SBE }\end{array}$ & $\begin{array}{c}\text { Biodiesel specification } \\
\text { EN14214 }\end{array}$ \\
\hline Esters content & wt. $\%$ & $96.8 \pm 0.3$ & EN $1410396.5(\min )$ \\
\hline Density & $\mathrm{kg} \mathrm{m}^{-3}$ & 873 & $\begin{array}{l}\text { EN ISO } 12185 \\
860-900\end{array}$ \\
\hline Viscosity & $\mathrm{cP}$ & 3.2 & $3.5-5.0$ \\
\hline Acid value & $\mathrm{mg} \mathrm{g}^{-1} \mathrm{KOH}$ & 0.4 & EN 14104-0.5 (max) \\
\hline Iodine value & $\mathrm{g} \mathrm{I}_{2} / 100 \mathrm{~g}$ & 104 & EN 14111- $130(\max )$ \\
\hline Flash point & ${ }^{\circ} \mathrm{C}$ & 164 & EN ISO 3679120120 (min) \\
\hline Cloud point & ${ }^{\circ} \mathrm{C}$ & 10 & EN 23015 \\
\hline Moisture content & $\mathrm{mg} / \mathrm{kg}$ & 300 & EN ISO 12937- 500 (max) \\
\hline
\end{tabular}

\section{CONCLUSIONS}

In this paper, Calcium from limestone has been successfully loaded onto POR-SBE as a catalyst in transesterification of waste frying oil. Optimized conditions found to be 12:1 methanol to oil molar ratio; for Ca-POR-SBE as catalyst the optimum are $4 \mathrm{~h}$ reaction time and $7 \mathrm{wt} . \%$ catalyst amount achieving $96.8 \%$ conversion. Utilization of POR-SBE as an eco-friendly and cheap solid support is a promising.

\section{ACKOWLEDGEMENT}

The authors acknowledge the Ministry of Higher Education Indonesia for funding the research through HIBAH Fundamental, Mulawarman University and Universiti Malaysia Pahang.

\section{REFERENCES}

US Energy Information Administration (EIA). Annual Energy Outlook 2011 with Projections to 2035. $<$ http://205.254.135.7/ forecasts/aeo/er/early elecgen.cfm $>(\mathrm{Ma}$ y 2016).

Abdullah, A.Z., Razali, N., Lee, K.T. 2009. Optimization of mesoporous K/SBA-15 catalyzed transesterification of palm oil using response surface methodology. Fuel Processing Technology. 90 : 958-964.

Agrawal, S., Singh, B., Sharma, Y.C. 2012. Exoskeleton of a Mollusk (Pila globosa) as a heterogeneous catalyst for synthesis of biodiesel using frying oil. Industrial \& Engineering Chemistry Research. 51 : 11875-11880.

Alim, M.A., Lee, J.H., Akoh, C.C., Choi, M.S., Jeon, M.S., Shin, J.A., Lee, K.T. 2008.

Enzymatic transesterification of fractionated rice bran oil with conjugated linoleic acid: Optimization by response surface methodology. LWT - Food Science and Technology. 41 : 764-770.

Boey, P.-L., Maniam, G.P., Hamid, S.A. 2009. Biodiesel production via transesterification of palm olein using waste mud crab (Scylla serrata) shell as a heterogeneous catalyst. Bioresources Technology. 100 : 6362-6368. 
Boey, P.-L., Maniam, G.P., Hamid, S.A., Ali, D.M.H. 2011. Utilization of waste cockle shell (Anadara granosa) in biodiesel production from palm olein: Optimization using response surface methodology. Fuel. 90: 2353-2358.

EIA, 2014. Energy Information Administration. Monthly Biodiesel Production Report.

Lee, H.V., Yunus, R., Juan, J.C., Taufiq-Yap, Y.H. 2011. Process optimization design for jatropha-based biodiesel production using response surface methodology. Fuel Processing Technology. 92 : 2420-2428.

Liao, C.-C., Chung, T.-W. 2013. Optimization of process conditions using response surface methodology for the microwave-assisted transesterification of Jatropha oil with $\mathrm{KOH}$ impregnated $\mathrm{CaO}$ as catalyst. Chemical Engineering Research and Design. 91: 2457-2464.

Limmanee, S., Naree, T., Bunyakiat, K., Ngamcharussrivichai, C. 2013. Mixed oxides of $\mathrm{Ca}, \mathrm{Mg}$ and $\mathrm{Zn}$ as heterogeneous base catalysts for the synthesis of palm kernel oil methyl esters. Chemical Engineering Journal. 225: 616-624.

Reyero, I., Arzamendi, G., Gandía, L.M. 2014. Heterogenization of the biodiesel synthesis catalysis: $\mathrm{CaO}$ and novel calcium compounds as transesterification catalysts. Chemical Engineering Research and Design. 92: 1519-1530.

Rodrigues, R.C., Ayub, M.A.Z. 2011. Effects of the combined use of Thermomyces lanuginosus and Rhizomucor miehei lipases for the transesterification and hydrolysis of soybean oil. Process Biochemistry. 46: 682-688.

Salamatinia, B., Mootabadi, H., Bhatia, S., Abdullah, A.Z. 2010. Optimization of ultrasonic-assisted heterogeneous biodiesel production from palm oil: A response surface methodology approach. Fuel Processing Technology 91: 441-448.

Shieh, C.J., Liao, H.F., Lee, C.C. 2003. Optimization of lipase-catalyzed biodiesel by response surface methodology. Bioresources Technology. 88: 103-106.

Silva, G.F., Camargo, F.L., Ferreira, A.L.O. 2011. Application of response surface methodology for optimization of biodiesel production by transesterification of soybean oil with ethanol. Fuel Processing Technology. 92: 407-413.

Tang, S., Wang, L., Zhang, Y., Li, S., Tian, S., Wang, B. 2012. Study on preparation of $\mathrm{Ca} / \mathrm{Al} / \mathrm{Fe}_{3} \mathrm{O}_{4}$ magnetic composite solid catalyst and its application in biodiesel transesterification. Fuel Processing Technology. 95: 84-89.

Teo, S.H., Taufiq-Yap, Y.H., Ng, F.L. 2014. Alumina supported/unsupported mixed oxides of $\mathrm{Ca}$ and $\mathrm{Mg}$ as heterogeneous catalysts for transesterification of Nannochloropsis sp. microalga's oil. Energy Conversion and Management. 88:11931199 . 